\title{
EUROPEAN PERSPECTIVES ON COMPETITIVENESS AND RESEARCH IN A KNOWLEDGE-BASED ECONOMY. WHERE DOES ROMANIA STAND?
}

\author{
Monica Boldea ${ }^{l}$ \\ Maria Otil ${ }^{2}$ \\ Ionut Dragoi ${ }^{3}$
}

\begin{abstract}
In order to cope with the challenges of globalization Europe will have to focus on its creative and innovative capacity, creativity and innovation being crucial in meeting global challenges, this being the more evident given the current economic crisis. Our paper analyzes the $E U$ cohesion policy (as a tool for addressing challenges in the long run) on regional development, as well as the regions' role in the economic development with regard to research and innovation, in order to lead towards a strengthening of competitiveness. We also question to what extent is encouraging research-development-innovation a priority for Romania, given the European standpoint. Our study is mainly based on data provided by various communications from the European Commission, EUROSTAT, and the Statistical Yearbook of Romania.
\end{abstract}

Key words: economic development, regional policy, $R \& D$, competitiveness, innovation

JEL codes: E6, R12

\section{Introduction}

If 2008 was appointed by the European Commission to be the European Year of Intercultural Dialogue, 2009 was appointed as the European Year of Creativity and Innovation, the main objective aiming to promote creativity as the drive for innovation and as key factor in the development of personal, occupational, entrepreneurial and social skills through lifelong learning, the modern world focusing on the more effective use of knowledge and innovation. In this regard, extending the creative abilities of the entire population, especially of those which enable people to change and be open to new ideas within a diverse society in terms of cultural knowledge, is mandatory. While education and culture are in the spotlight throughout 2009, creativity and innovation for many other spheres of activity, such as business, technology, employment or regional policy.

The measures put forward to promote creativity and the capability for innovation will be tailored to fit each stage of the lifelong learning process, up to the post-retirement stage. In this regard, Europe will have to focus on the creative and innovative capacity in order to cope with the challenges of globalization, creativity and innovation being crucial in meeting global challenges, this being the more evident given the current economic crisis.

At the core of any future development is the stimulation of the transition toward a knowledge-based economy requiring more and better co-ordinated efforts in various areas such as education, research and innovation. Scientific and technological research represents, as main generator of new knowledge and source of future competitiveness, a main pillar of this transition. As far as research is concerned, the current situation of Europe is positive in various areas. With

1 West University of Timişoara, Faculty of Economics and Business Administration, e-mail: monica.boldea@feaa.uvt.ro

${ }^{2}$ West University of Timişoara, Faculty of Economics and Business Administration, e-mail: maria.otil@feaa.uvt.ro

${ }^{3}$ West University of Timişoara, Faculty of Economics and Business Administration, e-mail: ionut@dmi-it.ro 
regard to education, and in particular tertiary education, surely it not only renews stocks of human capital but also promotes economic growth. Therefore, investment in education can be seen much more as an investment in future economic well-being rather than as an investment in individual success. The role of human resources, educated and employed in science and technology occupations ('highly-qualified S\&T workers'), is fundamental in knowledge-driven economies, because these people contribute directly to the expansion of R\&D activities and to the development of technological innovations. Innovation comes from people, and only people - scientists, researchers, entrepreneurs and their employees, investors, consumers and public authorities - will make Europe more innovative. But they do not act in a vacuum. They act with a mindset and in a framework which either discourages or incites them to enter unknown territories.

\section{A Europe „of” or „with" regions? The regions' role in the economic development}

Nowadays, Europe is composed of a mosaic of regions, which are the result of the society's socio-economic and cultural diversity. After the entry into force of the Maastricht Treaty, the regions have become one of the pillars of the European integration. The EU cohesion policy on regional development is a priority concern of the EU at present. Therefore, a country that aspires to become an EU member country, and further to integrate successfully, has to fit both the European spirit and authenticity, having to pay increased attention to preparing its territory to meet the demands pointed out by the Union to its member countries, developing a sound and active regional policy. The EU regional policies are implemented taking into account the needs acknowledged by the civil society, each Member State developing policies and implementing appropriate procedures; the regions, which are the states' integrative parts, are especially important if they are viewed in the light of the steps that are needed to be taken by the Member States.

The European cohesion policy is mainly a tool for addressing challenges on medium and long term. This means that, given its nature, it can not be considered an anti-cyclical policy or a crisis management tool; however, the European cohesion policy has an important role to play in solving the current crisis. Four major advantages can be highlighted:

1) it leads to confidence regaining and investment procedures starting at municipality and regional level.

2) it is a tool based on solidarity, which means it can trigger the positive significance of the crossborder cooperation in a time of political scission within the EU.

3) it aims at supporting long-term structural reform, so that investments should keep their "acumen" and "trust" particularly in a time when short-term prospects prevail.

4) it represents one third of the EU budget and provides the maximum potential results in financial terms in a time of financial crisis, constituting a seldom opportunity. This is materialized by the use of resources for "green" investment or support SMEs' lending, anticipating the funds available for local and regional authorities that have a greater need for having their investments backed up, while maintaining an acceptable level of public services

European policy-makers have called for the introduction of the territorial dimension in the Lisbon Strategy, so that the regions' particular characteristics should be taken into account. However, the application of the cohesion policy cannot be narrowed down only to the goals of the Lisbon Strategy. The lever effect triggered by the structural funding can be enhanced by private cofinancing, hence the rapid introduction of new regulations required by deputies, as well as clear rules for the development of public-private partnerships models that would allow regions to use private capital for public purposes.

Much debated was also the governance on several levels - national, regional and local particularly the importance it has in the establishment and implementation of regional development objectives. Territorial cohesion is the logical consequence of an integrated common market. As long as goods, persons, capital and services are granted free traffic throughout Europe, it must also be ensured that people can freely choose where to live; choosing a rural or urban area should not be 
involve lack of access to indispensable public services. In other words, territorial cohesion is ensuring that European citizens have equal opportunities to develop their talents and enjoy their fundamental rights, whatever their place of work or residence.

The regions - as sub-national geographical entities - become more and more aware of the impact which research and innovation may have on economic development, many regions allotting, in their regional development policies, priority and funding to research and development. The majority of the regions have established economic development policies or programs within the framework of their operational programs and national/regional plans, in this context many regions having established a variety of innovation strategies aimed at certain domains or sectors (e.g. information society strategy, tourism development strategy). Generally, the regional policies focus on creating links and on developing diffusion and absorptive capacities; on the other hand, national research and technological development policies - mainly funded by national governments - are still the major sources of funding for research infrastructure and knowledge creation, even in highly decentralized countries. This may explain, however, why the majority of European regions do not show increased interest in investing in research and technological development per se, but rather focus on the contribution of research and technological development to broader development goals, issues as how to determine and support economic growth, how to cope with the impact of industry's relocation abroad, how to increase employment and at the same time increase citizens' economic welfare being a few of the most prominent (regional) challenges policy-makers are currently concerned with. In the case of the majority of regions increasing R\&D investment does not have a significant automatic and immediate impact on growth and job creation due to the fact that technological change - as an outcome of research - is only one way to generate wealth, this way failing to be the most important concern. Definitely, increased investment in research can positively contribute to wealth and job creation within regions, but we should also face the fact that the level of impact varies according to the type of European region, the level of impact being highly dependant on the regions' absorption capacity, and this leads us back to techno-economic characteristics and economic specialization. It can also be assumed that if regions have relatively stable techno-economic characteristics over a longer period of time they can be expected to adopt similar research (RTD) policy approaches. However, even similar measures might have different impacts in different regions depending on how they are implemented.

\section{Regional development vs. competitiveness - what exactly prevails in the economic and social cohesion strategy for 2007-2013?}

Faced with the prerequisite of including a regional development policy in the context of national economies, which should fit the European Commission's provisions, the less developed states have adopted the most convenient and adjustable solution for their situation, respectively the implementation of a regional policy which should focus on supporting the competitiveness of certain regions rather than waste the few resources throughout their territory, given that only capital cities and some of the relatively developed areas were the only regions able to compete internationally, at least for a while. However, the harmonious development of the entire territory of the European Union requires a regional development policy capable of working even in the regions which are lagging behind, giving way to also apply the principle of creating equal living conditions for all inhabitants of a country, considering as being unfair to abandon certain regions of the country due to market pressures. Practice has shown that economic policy objectives may be contradictory - this aspect also assuming that one and the same mechanism can not be used to reach diametrically opposed objectives, i.e. both in an expansionary and a restrictive trend. The progress in the long-term development of already prosperous regions may lead to unequal levels of development, to the congestion of problems that already exist in other regions, to pollution, and also to inflationary pressures due to activity concentration and interregional migration. 
Is the European regional development policy supposed to strengthen competitiveness, cohesion, or both of them? It is generally accepted that the competitiveness of both business enterprises and public institutions in a region is a key factor in its economic development and, therefore, for the maintenance of a high level of employment. Competitiveness in turn is heavily influenced by the ability of companies to innovate, to introduce new products and new techniques in the production process. Innovation can result either from the transfer of technology and know-how from outside the region - or company - or from companies in the region undertaking their own research and technological development (RTD). In the past, RTD was generally seen as a linear process, starting with basic research, leading to applied research and technological development and culminating in demonstration projects or prototypes. Accordingly, public policy often concentrated on the supply-side, especially on infrastructure, with large-scale investment in major research centers for undertaking basic research. Today the effectiveness of this approach, particularly for the development of less favored regions, is open to doubt. Policies to support and improve research, innovation, education and training, and so promote an innovation culture, are increasingly centered on the creation of networks, or clusters, to stimulate innovation in SMEs and to ensure the wide dissemination of research results. The aim is to maximize the spillovers from scientific and technological advances and to encourage their incorporation in the production process.

Empirical analysis suggests that growth of research and technology development (RTD) output by region (measured by the increase in patents per head population) is closely correlated with growth of GDP, once extreme cases (regions with very low patent intensity or very high growth rates) are excluded. It suggests, in addition, that there is also a positive association between growth and the proportion of SMEs in a region, which are innovative, when account is taken of regional differences in the level of technology. Although such relationships do not prove that the direction of causality runs from innovation to growth, it provides some support for a policy of encouraging RTD as a means of stimulating economic development. At the same time, not all regions need to be leaders in RTD, or even in technology-intensive industries, to attain high levels of GDP per head. The Balearic Islands in Spain, for example, have the lowest ratio of gross expenditure on RTD (GERD) to GDP of all Spanish regions but the highest level of GDP per head, thanks to a highly successful tourist industry.

Regional competitiveness depends on the markets' productivity and accessibility, on the qualification level of employment and on 'institutional factors', such as social capital endowment in the form of entrepreneurial culture, that encourage cooperation and initiative and further contribute to effective public administration.

During 2007-2013, the credit management system will direct $64 \%$ of the "convergence" resources and $80 \%$ of the "Regional competitiveness and employment" resources to cover the costs of innovation. The use of these loans depends, however, on the ability of the less developed regions to manage numerous and well prepared research, development and innovation projects, to ensure that they will be actually used and not redirected towards investment with low added value; this was clearly pointed out in the European Commission's report assessing whether Regional Development Funds should be used to develop the Lisbon strategy or to reduce disparities in development between regions.

Innovations take place at regional level, the regions comprising the drive for innovation, creativity, dynamism and European entrepreneurial spirit. As the Council of Europe has aptly put it, a solid regional cultural identity leads to economic growth and social cohesion.

In 2007, at EU level, 229 billion euro have been spent on research and development activities, a level which, calculated as a percentage of the EU's GDP was of $1.85 \%$, at the same level as in 2006. According to Eurostat data, the share of gross domestic expenditure on R\&D in GDP decreased between 2000 and 2007 from 1.85\% to 1.83\%. This indicator thus shows a move away from the EU target of $3 \%$ by 2010 . A comparative analysis also shows that Europe devotes a much lower share of its wealth to R\&D than the US or Japan; China, on the other hand, having had 
a lower R\&D intensity, grew constantly, having this way the possibility of spending the same amount of GDP on research as the EU by 2010 - about 2,2\% - if the trend continues. The most worrying conclusion of the key figures is that Europe tends to become a less attractive place to carry out research, R\&D expenditure by EU companies in the US increasing much faster than R\&D expenditure by US firms in the EU (54\% compared to 38\%). Additionally, US investment has been growing at a much higher rate in areas outside the EU - about $8 \%$ per year in the EU and $25 \%$ per year in China.

In Romania, research and development expenses totaled 653 million euro in 2007 and its percentage of the GDP was of $0.53 \%$, slightly increased compared to $0.45 \%$ in 2006 , but still among the lowest levels in the EU. However, according to available data analyzed by Eurostat, Romania outruns countries like Cyprus $(0.45 \%)$, Slovakia $(0.46 \%)$ and Bulgaria $(0.48 \%)$. By contrast, champions in R \& D expenditure in 2007 were Sweden (3.60\% of the GDP), Finland (3.47\% of the GDP) and Austria (2.56\% of the GDP).

If S\&T is a key element of knowledge, the numbers of R\&D personnel and in particular, researchers are key indicators of its dissemination and development as they demonstrate the human resources going directly into $R \& D$ activities. In terms of full-time staff in the research and development sector, at EU level in 2007 the number of employees was of over 2 million people, corresponding to $1.6 \%$ of the total number of employees in the EU for that year. As can be noticed in the graph below (graph no.1), Germany and France were the most important R\&D employers within the EU, surpassing $40 \%$ of the EU's R\&D personnel employed in these two countries. 


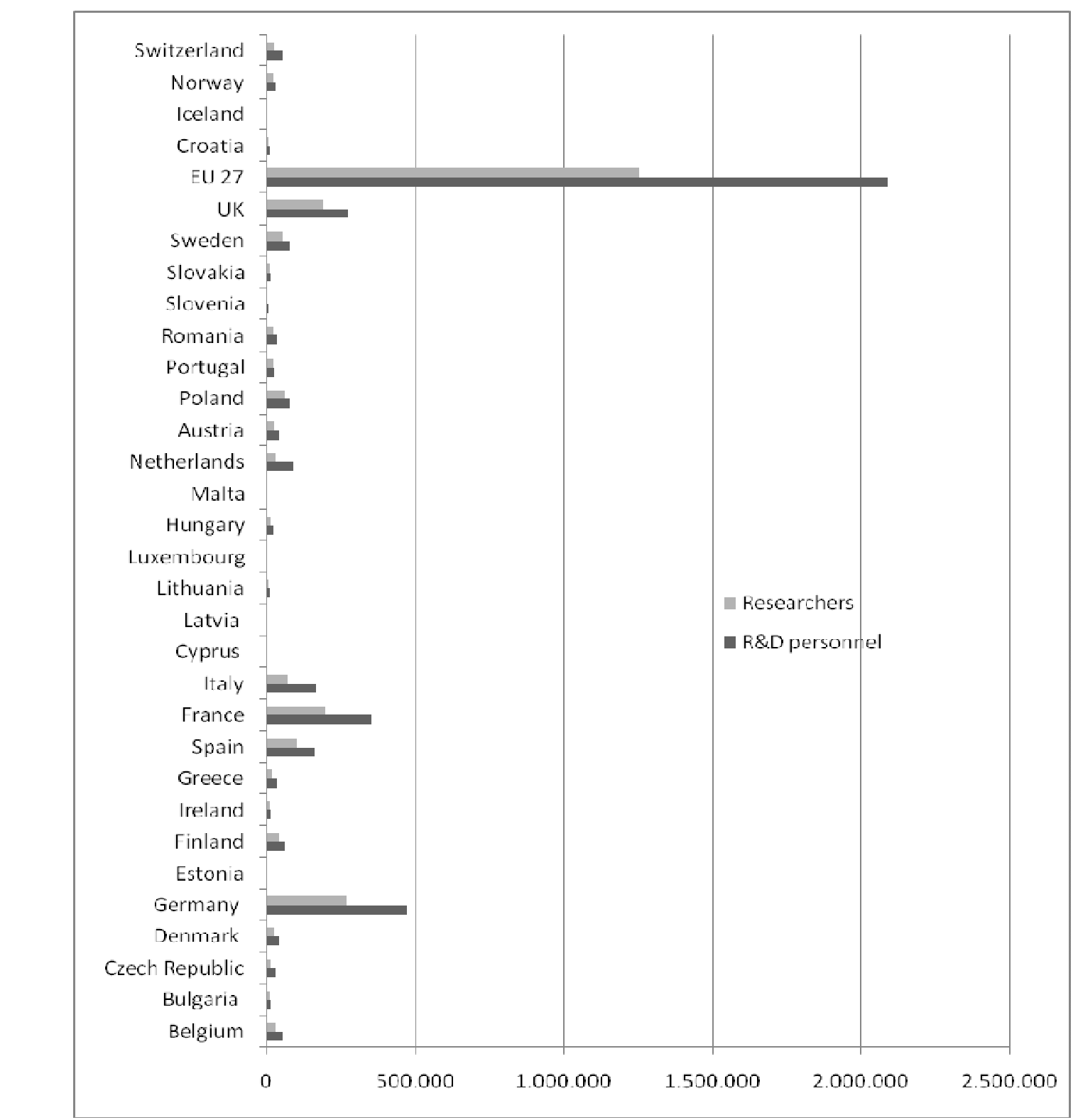

Source: DG Research

Key Figures 2007

Data: Eurostat

Fig. no. 1 - Total R\&D personnel and researchers (all sectors - business enterprises, government, higher education, including private non-profit organizations)

Among the new Member States, the main countries employing R\&D personnel were Poland, Romania and the Czech Republic. With the exception of the Czech Republic, Malta and Romania, most of the R\&D personnel in the new Member States were employed in the public sector (government and higher education). This is in contrast to most of the other Member States, where the private sector accounted for the highest share. In Romania, at the level of 2007, the personnel in $\mathrm{R} \& \mathrm{D}$ comprised around 33,000 employees, the equivalent to $0.6 \%$ of the total number of employees, one of the lowest percentages in the EU, followed by Poland with a rate of $0.8 \%$ in 2007. For the period of 2004-2006, in the EU 39\% of firms in industry and services at least 10 employees have developed some innovative activities. If the highest percentages were recorded in Germany (63\% of enterprises), Belgium (52\%), Austria and Finland (both 51\% each) and 
Luxembourg (49\%), the lowest percentages were recorded in Latvia (16\%), Bulgaria and Hungary (both 20\% each), Romania (21\%) and Lithuania (22\%).

\section{Encouraging research-development-innovation - priority for Romania? An analysis of inter-regional disparities.}

One of the factors that enhance competitiveness is the development of the research and development sector. In Romania, research and development has, still, weak links with the economic environment, having no significant contribution to the regional economic development. The development of knowledge economy, of industry clusters and of research-based clusters will jointly step up technology transfer.

The general political and economic trends forecast:

- the recognition of the R\&D sector's strategic importance for the sustainable and competitive economic development, given the provisions of the legislation specific to the field, (GD 57/2002 approved by Law 324/2003) and by including the research - development field in the structure of economic and social development strategies, both at general and sectorial levels;

- the strengthening of cooperation between companies and universities, as well as with research institutes, in order to become an important factor in the business infrastructure development perspective;

- the significant increase in the degree of correlation of policies in the field with other government policies (infrastructure, rural development, regional development, environment, etc.);

- the support of productive investments (new equipment and technologies) and also the support of the innovative capacity at corporate level, to ensure that production can meet the single European market requirements.

The entire research and development sector in Romania is undergoing a comprehensive process of restructuring and reorganization on a new basis. Research in Romania is extremely centralized, over $50 \%$ of researchers and of the funds directed to this field being still concentrated in the capital, namely the region Bucharest-Ilfov (Table no.1).

The number of researchers per 10,000 inhabitants in 2005 was of 100 in the region of Bucharest-Ilfov, while in other regions it varied between 7 (the South Region) and 12 (the Southeast Region), and in 2007 the following figures were recorded: 65, the other regions varying between 6 and 14. The most dramatic decrease in the number of researchers per 10,000 inhabitants occurred in the region Center - from 16 in 1999 to 10 in 2005, and in Bucharest-Ilfov region from 100 in 2005 to 65 in 2007, the decrease at national level being of smaller scale (from 21 to 19, respectively from 19 to 14$)$.

Table no. 1

Number of researchers per 10.000 inhabitants in the Romanian regions of development

\begin{tabular}{|c|c|c|c|}
\hline $\mathrm{P}_{\text {Region }}$ Year & 1999 & 2005 & 2007 \\
\hline Romania & 21 & 19 & 14 \\
\hline North - East & 9 & 10 & 9 \\
\hline South - East & 8 & 7 & 6 \\
\hline South Muntenia & 13 & 12 & 8 \\
\hline South - West Oltenia & 13 & 11 & 10 \\
\hline West & 10 & 10 & 10 \\
\hline North -West & 10 & 10 & 9 \\
\hline Centre & 16 & 10 & 9 \\
\hline Bucharest-Ilfov & 111 & 100 & 65 \\
\hline
\end{tabular}


One factor that may increase business competitiveness is the high share of researchers in the fields of technical sciences and engineering. Unfortunately, low salaries, material resources less appropriate to achieve proper performance, as well as opportunities for research programs promoted by other countries have led to a gradual decrease in the number of researchers.

The main issues facing the field are: the low level of financial backing from public funds $(0.53 \%$ of the GDP in 2007 [See table no. 2 The regions' share in the total expenditure on research and development at national level]); the outdated $\mathrm{R} \& \mathrm{D}$ infrastructure, failure to adjust to competitive market conditions, the decrease in the number of researchers and the increase of their average age. Another major problem consists of the still weak link between research and economy and the relatively scarce capability of putting the research results to good use.

Table no. 2

The regions' share in the total expenditure on research and development at national level

\begin{tabular}{|l|l|l|l|l|l|l|l|}
\hline $\begin{array}{l}\text { Total expenditure } \\
\text { on R\&D }\end{array}$ & $\mathbf{2 0 0 0}$ & $\mathbf{2 0 0 1}$ & $\mathbf{2 0 0 2}$ & $\mathbf{2 0 0 3}$ & $\mathbf{2 0 0 5}$ & $\mathbf{2 0 0 6}$ & $\mathbf{2 0 0 7}$ \\
\hline \% of the GDP & 0,37 & 0,39 & 0,38 & 0,39 & 0,41 & 0,45 & 0,53 \\
\hline \% at regional level & 100,00 & 100,00 & 100,00 & 100,00 & 100,00 & 100,00 & 100,00 \\
\hline North - East & 5,52 & 5,83 & 5,06 & 4,92 & 5,52 & 6,87 & 7,52 \\
\hline South-East & 6,29 & 6,15 & 4,59 & 3,47 & 3,59 & 3,47 & 3,71 \\
\hline South Muntenia & 13,27 & 14,09 & 15,82 & 13,91 & 11,34 & 9,31 & 10,64 \\
\hline $\begin{array}{l}\text { South West } \\
\text { Oltenia }\end{array}$ & 4,51 & 4,84 & 3,76 & 2,80 & 3,8 & 3,44 & 3,11 \\
\hline West & 5,51 & 3,79 & 4,63 & 6,11 & 4,46 & 4,43 & 5,12 \\
\hline North -Vest & 3,78 & 4,16 & 6,74 & 4,80 & 7,52 & 7,45 & 8,88 \\
\hline Centre & 7,81 & 6,05 & 6,70 & 6,66 & 4,49 & 3,89 & 3,42 \\
\hline Bucharest -Ilfov & 53,31 & 55,09 & 52,70 & 57,33 & 59,28 & 61,13 & 57,6 \\
\hline
\end{tabular}

R\&D expenses registered a modest dynamic in Romania so far, but due to increasing competition, $R \& D$ will be the one that will enable firms to withstand market pressures (Table no. 2). Invigorating innovation is, however, very important for increasing the added value, the longterm competitiveness and for ensuring Romanian companies' access on international markets, implicitly reducing the trade deficit. With this regard, it is necessary to support the innovative capacity of firms by providing proper assistance and consultancy, by ensuring access for financial backing, and by creating conditions for development.

As the graph below shows, the regions' share in the total R \& D expenditure at national level in 2007 is as follows (Graph no.2): 


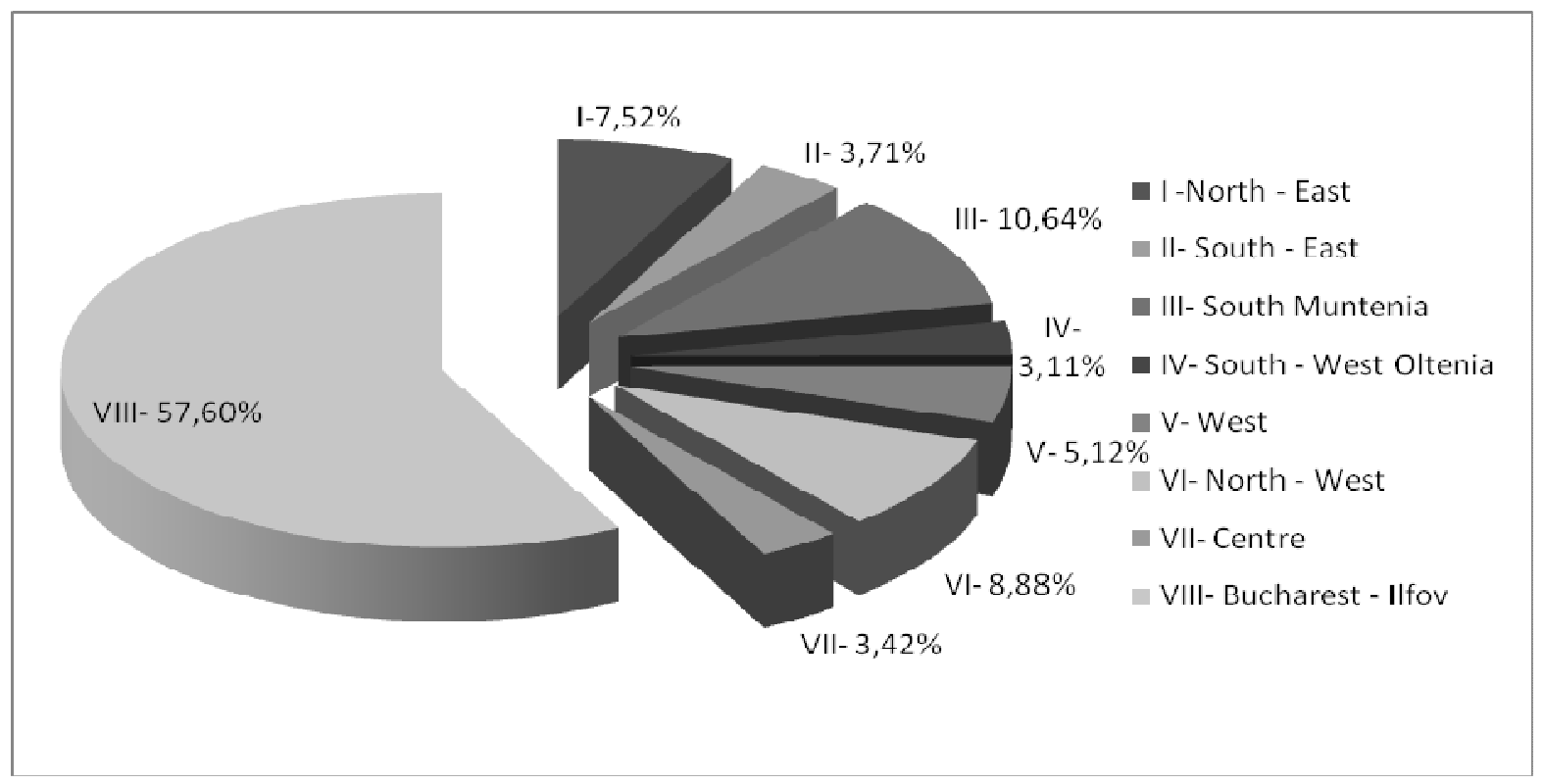

Fig. no. 2 - The regions' share in the total expenditure
on research and development at national level

The system of R\&D and innovation in Romania has gone through a long period of underfunding; between 1999 and 2004, the share in GDP of public spending on R \& D was about $0.38 \%$ (Table Nr. 2.23), more than three times lower than the EU average - of 25. In accordance with the Lisbon objective, starting with 2005 public expenditure for research, development, and innovation have registered an upward trend, targeting to reach 3\% in 2010. With this regard, the Ministry for European Affairs pointed out that "the Romanian authorities should take on a more serious role so as to encourage innovation and research, and efforts should be focused towards well defined areas, which could add value to the local economy and also to European competitiveness [...] a comprehensive qualitative restructuring being needed, which would accelerate Romania's modernization based on promoting innovation, creativity and research jointly with industrial, agricultural and social policies."

\section{Final conclusions of the study}

The main finding of our study is pointed out by the fact that the progress achieved in recent years shows that the EU has rightly identified innovation as a key driver for a prosperous future. However, making the EU a vibrant space for innovation requires continuous attention and calls for a better exploitation of the potential of the partnership between the Union and its Member States by taking more focused and better coordinated actions at all levels. According to the Lisbon strategic objectives, economic growth and sustainable development can only be achieved by supporting research and innovation in all economic and social fields, there being solid agreement on the fact that both economic growth and future competitiveness of the economy will be based on research and information.

Secondly, even if most European regions rather focus on the contribution of research and technological development to broader development goals, the developed regional strategy is aimed at increasing economic competitiveness, as it may contribute to the sustainable development of communities mainly through procedures providing the partnership between the private sector research and development - and the academic sector, promoting reduced energy consumption, exploitation of renewable energy sources and alternative technologies, resulting in products with high added value, and also promoting innovation. However, the regions, as integrative parts of the states, are not under the direct supervision of the European Union, the EU having no direct 
interference in the internal affairs; consequently, it is each state's responsibility to develop and implement solid and applicable regional policies, lest we forget that most European regions still have limited governance autonomy and research policy competencies.

We also questioned to what extent is encouraging research-development-innovation a priority for Romania. The study pointed out that this sector has to face both internally- and externally-driven problems. Those that are felt within the system of research and development are mainly scarce financial backing from public funds (the state's financial effort to support this sector is 80 times lower than in Western European countries), then the problem of outdated infrastructure, the problem raised by the human resource (mainly by the lack of it, the personnel activating in this sector decreasing gradually, the aging of it also raising some concern. Among the externally-driven problems, there is still limited capacity to absorb the results of research by economic agents (not all research institutions have easily adapted to the market economy conditions, many of which are still dependent on government funding, finding no economic partners interested in the research results) as well as the relatively low interest of the economic agents in R \& D and innovation (and therefore a low level of private funding). Although there is increased potential for development of $R \& D$, this sector faces a downward trend at present, being mandatory to take the appropriate measures to increase the interest of regional actors (businesses, public authorities, civil society, human resources involved) in order to revitalize this sector.

\section{References}

1. Silasi, G., Rollet, Ph., Trandafir, N., Vădăsan, I., 2007, "Economia Uniunii Europene: O poveste de success?”, 2nd edition, Ed. Universităţii de Vest, Timişoara, (p.262-273);

2. ***, The Statistical Yearbook of Romania, 2008, available on-line at http://www.insse.ro/cms/rw/pages/anuarstatistic2007.ro.do (date of consultation 20.05.2009);

3. ***, The Development Plan of Region Center for the period 2007 - 2013, available online at www.adrcentru.ro , Bucharest, 2008 (date of consultation 24.03.2009);

4. "Reviewing Community innovation policy in a changing world", Communication from the Commission to the European Parliament, the Council, the European Economic and Social Committee and the Committee of the Regions, Brussels, 2.9.2009, COM(2009) 442 final, available on-line at http://www.spcr.cz/files/com2009442final en.pdf (date of consultation 09.09.2009);

5. "Science, Technology and Innovation in Europe, R\&D expenditure in the EU27 stable at $1.85 \%$ of GDP in 2007", EUROSTAT news release, 127/2009 - 8 September 2009, available online at http://epp.eurostat.ec.europa.eu/cache/ITY_PUBLIC/9-08092009-AP/EN/9-08092009-APEN.PDF (date of consultation 08.09.2009);

6. Van den Brande, Luc, "Orice plan "national" de redresare economica are sanse numai cand ia in calcul regiunile", 06.03.2009, (date of consultation 20.05.2009) available on-line at

http://www.euractiv.ro/uniunea-europeana/articles/displayArticle/articleID_16630

7. The Lisbon strategy and the new dynamics for science, technology and innovation, available on-line at $\mathrm{ftp}: / / \mathrm{ftp}$.cordis.europa.eu/pub/indicators/docs/3rd report snaps0.pdf , (date of consultation 18.05.2009);

8. "Towards a European Research Area. Science, Technology and Innovation. Key Figures 2007”, European Commission, Directorate-General for research, Luxembourg: Office for Official Publications of the European Communities, 2007, available on-line at

9. "Mainstreaming sustainable development into EU policies: 2009 Review of the European ftp://ftp.cordis.europa.eu/pub/era/docs/keyfigures_2007.pdf (date of consultation Union Strategy for Sustainable Development", Communication from the Commission to the European Parliament, the Council, the European Economic and Social Committee and the Committee of the Regions, Brussels, 24.7.2009, $\operatorname{COM(2009)~} 400$ final, available on-line at http://ec.europa.eu/sustainable/docs/com_2009 400 en.pdf (date of consultation 09.09.2009). 